\title{
Effects of Conservation-induced Displacement on the Bacha of Southwest Ethiopia
}

\begin{abstract}
Deresse Daniel $^{\dagger}$ and Abeje Berhanu*
Abstract

This paper examines the impact of conservation-induced displacement on the Bacha community resulting from the establishment of Chebera-Chuchura National Park in Konta Special Woreda, Southern Nations, Nationalities and Peoples Region (SNNPR). It attempts to reconstruct the customary functions that the forestland had played for the livelihoods of the Bacha community and its role in cementing reciprocal relations among different social groups in pre-eviction contexts. The study employed a combination of both qualitative and quantitative research tools including in-depth interviews, key informant interviews, focus group discussions, field observations and household survey. Michael Cernea's analytical framework to assess the risks associated with displacement - Impoverishment Risk and Reconstruction (IRR) - is employed to see the multifaceted aspects of conservation-induced displacement. The findings revealed that in spite of the fact that displaced Bacha people have enjoyed greater level of access to land they suffered loss of entitlements to forest-based assets such as honey and plants of enormous medicinal value. The community also faced loss of job opportunities due to restrictions imposed on access to forestland that supported beneficial biodiversity for the livelihood of the Bacha people. Also adversely affected are inter-community relations built on reciprocal exchange of goods and services between the Bacha and neighboring farming communities. Now, the Bacha have faced the difficult task of adapting to the land-based crop farming as a new source of livelihood since they lack the necessary farming skills to make a living out of crop farming.
\end{abstract}

Keywords: displacement, livelihood, marginalization, Bacha

DOI: https://dx.doi.org/10.4314/ejossah.v14i2.2

${ }^{\dagger}$ Lecturer, Department of Sociology, Mizan-Tepi University, Email: deressedaniel2020@gmail.com, Tel: +251917003502 , P.O. box: 21/ Mizan

${ }^{*}$ Corresponding Author: Associate Professor, Department of Sociology, Addis Ababa University, Email: abejeye2010@gmail.com, Tel: +251911469122, P.O. box: 1176/ Addis Ababa

This work is licensed to the publisher under the Creative Commons Attribution-NonCommercialNoDerivs License. 


\section{Background of the Study}

Natural resources-based tourism is one of the ever-expanding industries of the world (Peluso, 1993). Its proliferation is built on initiatives capturing natural landscapes that have remained either untapped or serving wide range of socioeconomic purposes for local communities (Huhtala, 2007). State-backed moves to protect natural landscapes have also helped to promote tourism as the world's smokeless industry. The evidence shows the total size of land allocated for tourism at the beginning of the $20^{\text {th }}$ century was $500,000 \mathrm{~km}^{2}$, but it reached $3,500,000 \mathrm{~km}^{2}$ by 1990 (Brokington, 2004) resulting from government efforts to demarcate forest and bush lands into national parks at the expense of local communities. For example, in 1995 more than $500,000 \mathrm{~km}^{2}$ of land was put out of local peoples' access globally due to restrictions related to state-sponsored conservation but a decade later this figure doubled (Brokington, 2004).

In Ethiopia, the establishment of national parks in most circumstances has been guided by principles which viewed locals as potential enemies of conservation zones (Sato, 2000). Consequently, local communities had been restricted access to forests and forest products under the name of conservation. Desalegn (2004) reports on the prohibition of local population from thawing resources from the forest in the 1960s and 70s while these resources had always enabled the local farming communities to obtain their livelihoods. Following the technical and expertise advice from UNESCO, Haileselassie's regime came to realize the importance of establishing natural parks and protected areas of abundant wildlife and landscape beauty which would be in turn sources of tourist revenue and national revenue. The report further recommended 'best' conservation practices of the time that led to the creation of exclusionary zones aimed at preventing large scale hunting and habitat destruction (Desalegn, 2004). For example, the establishment of the Semien Mountain National Park by the Negaret Gazeta of 31 October 1969 (EWCA, 2015), which subsequently became World Heritage Site in 1978, could be seen as the government's effort to embrace the principles of conservation of nature by establishing natural enclosures in the form of national parks.

Concerning the pastoralists, the government has tolerated customary use of natural resources. However, this tradition of tolerating pastoralists seems to have significantly taken a new path, especially with emergence of conservation institutions from federal to local government levels (Meseret, 2006). The transition seems to be accompanied by change in the management of the natural resourcebase where national parks have been delegated for private companies like African parks (Brokington, 2004). Studies conducted on conservation (Dereje, 2006) have 
also recommended the necessity of removing indigenous communities like 'Tsara' and 'Bacha' from Chebera-Churchura National Park as they were considered to be a threat for the wellbeing of flora and fauna (Dereje, 2006).

Although there has been a decline in global trends of allocating forestlands at the expense of locals for the promotion of socio-economic development, there have been aggressive moves by the Ethiopian state, especially in the Southwest, which has always hosted communities who utilized forest resources in their livelihood strategy (Meseret, 2008; Dereje, 2006). One of the forestlands in Southwestern Ethiopia, which has been elevated to national park in 2005 by the SNNPR, is Chebera-Churchura National Park. The park is located $460 \mathrm{~km}$ southwest of Addis Ababa in the Gibe Omo basin between Dawro Zone and Konta Special Woreda. The establishment of the park was followed by forceful relocation of some 40 of the total 250 displaced households on its northern age. The move was resisted by the locals. Hence, the regional government was forced to allow, especially elderly households to stay inside the conservation zone (Meseret, 2006). Eviction from their natural resource-based livelihoods, however, has been intensifying in explicit and implicit measures denying communities' access to their accustomed mode of survival.

The paper investigates the impact of establishment of the national park on the livelihoods and social fabrics arrangements of the Bacha community by examining the significance of forest-based products in the livelihood strategies of the Bacha community and their contribution to the integration of the Bacha and the neighboring farming communities.

\section{Theoretical and Empirical Considerations}

\section{Understanding Displacement and Associated Risks}

Displacement of communities due to state induced intervention entails two major occurrences. The widely conceived format is the one that is manifested in relation to shifts in physical resettlement of communities when their continuation in the customary situation is in conflict with the aspired project or planned development (Schmidt, 2003). The second form of displacement often takes place in rural environment where state agencies instill new rules and property regimes for conservation of biodiversity and advancement of economic plans having the goal of boosting the national economy (Desalegn, 2004). On top of being restricted to collect firewood or wild foods, hunt or fish, the local communities dwelling on the edge of the park were forced to walk to their farms in a roundabout way, obliged to avoid the park. 
Thus the communities would be unable to live as they were before because of restrictions placed on them by government regulations. It is vital to conceive of displacement not only in its physical layout but also in its economic terms where disruption occurs to communities' livelihood activities and a wide range of intricate social processes that are essential building blocks on the process of making a living and ensuring sustainable livelihoods (Mathur, 1998).

Brokington (1998) extends our understanding of displacement that includes erecting fences with the intent of banning physical and economic access to natural resources in the name of natural forest restoration and/or conservation. Displacement thus comprises issues ranging from geographical to economic and cultural levels of exclusion and has multifaceted implications for the affected communities. The study applies Cernea's (2005a) analytical model- Impoverishment Risks and Reconstruction (IRR)-to closely scrutinize the multi-faceted aspects of displacement related to the study population in context. The IRR model includes eight main components:

$>$ Landlessness which includes expropriation of land assets and loss of access to land

$>$ Joblessness including when the eviction creates some temporary jobs

$>$ Homelessness i.e. loss of physical houses, family homes and cultural space

$>$ Marginalization as social, psychological and economic downward mobility

$>$ Food insecurity

$>$ Increased morbidity and mortality

$>$ Social disarticulation such as disempowerment and disruption to social institutions

$>$ Loss of access to common property like forests, water, wasteland, and cultural sites

Lands taken over by authorities through their explicit intervention for the purpose of socio-economic development or conservation alienate people and reduce them to a status of landlessness, thereby leading to further impoverishment (Cemea, 1999). Households or tribal groups face interference in their natural resources, social fabric, and livelihood arrangements for projects in the name of coal mining, conservation and dam construction. This happens to be the common experience in certain parts of the world causing displacement and exposing communities for a more complicated risk (Cernea, 1999). These risks are often unavoidable and continue to affect subjects of eviction even when the community is treated in the form of compensation for the loss of land (Nayak, 2000). 
Efforts to measure the empirical consequences of landlessness in terms of income earnings and livelihood disruption, for example, in Kenya, Indonesia, India and Brazil, reveal the decline in income and disruption of livelihoods compared to pre-intervention contexts (Reddy, 1999). This study, however, attempts to look at the context of economic eviction resulting from the loss of land by people with neither agrarian nor pastoral alternatives for their livelihoods. Such people have a peculiar livelihood as their survival exclusively depends on forest products. Compensations in the form of land replacement and livestock restoration would not help them avoid or reduce impoverishment since their livelihood is closely connected with the forest.

In addition to landlessness, displaced people also face joblessness which is the immediate aftermath of state-led conservation-induced displacement. It brings visible costs to people who are closely attached to the forest (Cernea, 2005a). The reality of joblessness becomes much higher especially among craftsmen and small business owners due to discontinuity in the demand and supply chain that acts as a strong pillar for the functioning of the alternatives (Pandey, 1996). This study focuses on the experiences of displaced communities that have been known to possess skills as a result of their exposure to a highly forested area that is rich in biodiversity. The skills enabled them to secure jobs that were desperately demanded by their neighboring communities. In this regard, the literature seems to shed light on the rise of joblessness due to loss of access to communal resource. Designing skill-focused packages might help them to make a smooth shift from their accustomed mode of living.

Eviction also results in marginalization mainly due to the shift in downward mobility of the economic status of displaced communities (Sam, 1996). Decline in alternatives of diversification and shift in relative status of subjects of eviction often puts people at positions prone to vulnerability in socio-economic terms (Cernea, 2005a). Some of the skills acquired through traditions and passed onto generations in the pre-displacement context become non-functional in the post-displacement context. They become unable to act as a means to yield incomes needed for the household. Marginalization is seen in contexts of not only economic conditions but also cultural levels. The other dimension of marginalization include the decline in relative prestige of displaced communities and their inability to exercise their usual cultural practices as they began to be perceived as strangers in their resettled new areas of settlement (Walter, 1991).

Eviction not only places people at risk of quantitative decline of food available for the household but also often enforces shift in the type of food consumed as people may not be adapted to it. For instance, Flakim (2000) reported 
on the experience of some resettled communities in the western state of Gujarat, India. They fundamentally transformed their livelihoods from food crops to cash crops due to eviction for dam construction. Displacement thus enforces involuntary shifts in the ways that people make their survival and consumption.

Displacement also results in increased vulnerability to risks of community health. Shifts in physical space and the environmental context of newly hosted settlements have the potential to exacerbate the segments of the community who are at the bottom of the demographic ladder, and are already weakened in their physical capacity due to involuntary mobility. Also, social organizations are found to be negatively affected by displacement due to the impact it has on the ways social organizations are formed and operated (Nayak, 1993). Disruptions occur to functions of social institutions as their existing frameworks no longer seem to exist (Cernea, 2005a). The social and cultural networks that are often organized along informal lines and are intended to play very crucial role in the pursuit of communities for sustaining life (mainly through inbuilt reciprocal relationships of exchange of valuables) are now forced to cease their function due to displacement.

Finally, displacement resulting from loss of access and claim for land due to state interferences would result in loss of home to community members who come under a risk of eviction. Such losses are not just confined to circumstances in which physical possessions are put under risk of loss but the various social spaces upon which many of the community life-ways are organized (Mathur, 1998). Displacement makes displaced families loose their previous position in home possession and face difficulty in adapting to new patterns of home ownership.

\section{State-Induced Displacement in Ethiopia}

In the context of Ethiopia, state induced displacement in the form of restriction of access to communal resource base has been a phenomenon that communities in Ethiopia at various conservation zones began to face since the mid 20th century (Desalegn, 2001; Kassahun, 2009; Piguet and Pankhurst, 2009). These policies favored the wellbeing of animal and biodiversity and viewed the customary interaction of people living next to it as an ultimate cause for the imbalance of the environment. The experience in state run conservation by the Ethiopian state has been a manifest continuity of the tradition in Africa, given the experience that the early interferences for conservation were intended to turn the inhibited lands to conducive locations and exclusionary zones dedicated for setting up a conservation area that would translate into economic growth (Turton, 1987). 
As indicated by Turton (1987) pastoralists in Ethiopia, for instance mainly the Mursi ethnic group, were made to hand over their environmental asset for the conservation scheme to create the Omo National Park. Similarly, the Karrayu and the Afar, because of the Awash National Park (Ayalew and Getachew, 2009) and the Guji Oromo of the Nechsar National Park (Tadesse, 2009) have suffered from conservation-induced displacement leading eventually to loss of access to grazing land, water and other natural resources vital for their survival. These moves provided access to only a marginal part of the conservation zones as restrictions begun to get more serious inside the exclusionary zones. The restricted areas had been functioning as a comfortable grazing area while pastoralists were engaging in seasonal migration (Turton, 1987).

The enclosure has been getting more serious especially in the recent past when the Ethiopian government transferred the right to possess and control certain national parks to private companies like African Parks. African Parks has been working very closely with governments that favore the privatization of everything including bio-diversity and wild animal (Brockington, 2010). The Nech-Sar National Park is the prime example as it was handed over to the private company and negotiations were underway for the removal of the Guji pastoralists who have utilized it for grazing their animals (SNNPR, 2013). Similarly environmentoriented NGOs and government institutions, which are showing concern on the matter, have recently begun to extend efforts that call for ever increasing measures to enhance restrictions aiming at banning communities' access to environmental resources (Dereje, 2006).

Generally, the empirical evidence suggests (Piguet and Alula, 2009; Ayalewand Getachew, 2009; Tadesse, 2009) that the government's primary concern regarding conservation-induced displacement has been to preserve and protect nature, wildlife and to promote eco-tourism. These same objectives guided the establishment of the Chebera-Churchura National Park and subsequent displacement of the Bacha from their natural forests and land.

\section{Methods}

\section{Description of the Study Area}

This study is conducted in Chebera Churchura National Park (SNNPR) where the Bacha people live (Figure 1). The national park is located in Konta Special Woreda and encompasses both highland and lowland features. The highlands are characterized by steep slopes and the lowlands in contrast are characterized by low altitude and gentle slopes (Dereje, 1993). The altitude of the area ranges from 550 to $2000 \mathrm{~m}$ a. s. 1 with flat lands and highly undulating terrains consisting rolling 
plains, incised rivers, streams, valleys, and gorges as dominant topographic features.

The Bacha people constitute a socially and economically marginalized group because of their closer proximity to the forest and their resultant forest-dependent mode of life. Our field observation and informal conversations with some members of the Bacha showed that physical confinement of the community to forestlands coupled with social marginalization by the neighboring farming communities has kept them unnoticed to the outside community. The peculiar socio-cultural identity of the Bacha has not been even known to the neighboring communities. Their cultures, symbols, and overall indigenous socio-cultural arrangements seem to remain subsumed by the dominant agrarian counterparts in their respective settlements. The surrounding farming population, which is practicing crop cultivation permanently, has been making a relentless but covert effort to confine the Bacha within the traditional low social ladder. It is often manifested in the form of, among others, restricting Bacha's interaction within and around the forestland and branding them as 'people of the forest' with limited interactions with the surrounding farming communities. The size of the population has not been recorded in official demographic and census documents but local sources (e.g. kebele source) give an estimate of 400 to 600 households living in the Konta Special Woreda. It is this group's relationship with the forestland, now the national park, which is the focus of this study. 


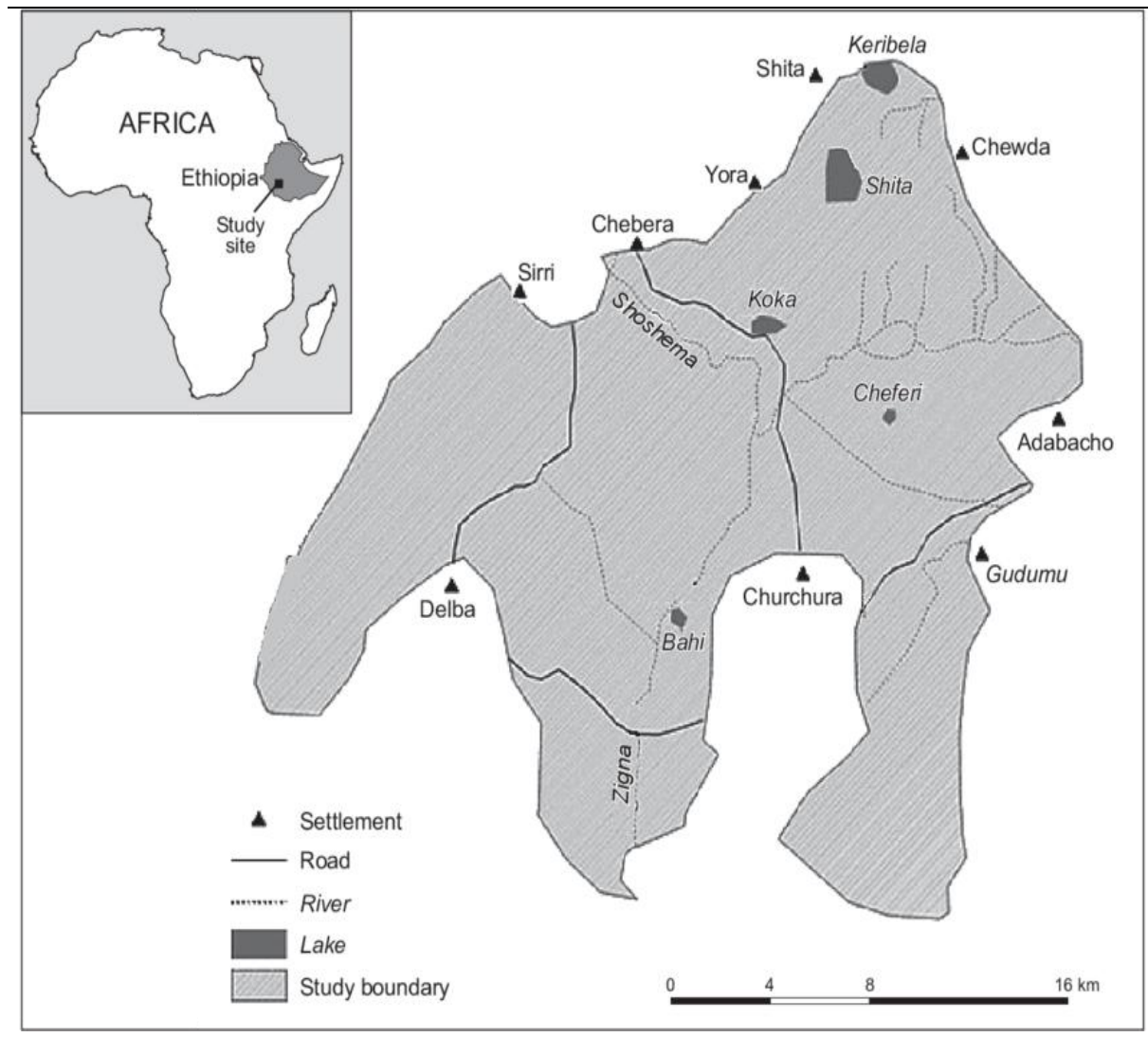

Figure 1: Location map of Chebera Churchura National Park (Google map)

\section{Tools for Data Collection and Analysis}

The data for this study were collected using both qualitative and quantitative data gathering tools. The first group includes: in-depth interviews, key informant interviews, focus group discussions and direct field observations while a questionnaire was employed to collect quantitative information.

Qualitative Interviews: In-depth interviews were used to obtain information related to the experience of the Bacha people who have been affected by eviction from their forest-based livelihoods. Those whose livelihood was organized around the use of plants for medicinal purposes which are demanded by the surrounding agrarian community as well as individuals who were employed by the National 
Park were given attention. Thus in-depth interviews were conducted with 5 men and 2 women whose ages were estimated to be above 60 . These informants were nominated based on their unique wisdom in relation to identifying medicinal plants for pathologies affecting both people and animals and the expectation that they could be the voice of their community.

Key informant interviews were held with individuals who were serving in local administration and had active roles in enforcing eviction rules on the Bacha people. It consisted of locals and officials of the national park who had a good deal of knowledge about the life and experiences of the Bacha people, both in pre-and post-displacement situations.

A total of 9 informants ( 7 men and 2 women) who participated in the government plan of converting the forestland to a national park gave information as key informants; 5 of them were government employees whereas the rest 4 were engaged in bridging state interest and community concerning the national park. The participants' ages ranged between 35 and 55 .

In addition, four focused-group discussions were conducted (two women FGDs and two men FGDs) with a view to obtaining a more collective and groupdriven view of the process and consequences of eviction from the forest resources. The participants' ages ranged from 35-65. Furthermore qualitative information was gathered through observation in the field. It was learnt that the community was banned from accessing forestland and forest resources (including preventing from harvesting honey and gathering medicinal plants). This was observed during a fieldwork by one of the authors who collected the data as part of his MA thesis research in Sociology in 2013 (Deresse, 2013). An observation checklist was prepared to distill out the most important matters needed to capture experiences of the community which the researchers might not uncover if they had not been making field observations.

Questionnaire Survey: Household heads that experienced eviction were interviewed using a questionnaire prepared for the purpose. The questionnaire was employed to collect quantitative data regarding livelihood activities, extent of asset loss due to eviction, socio-demographic features of individuals affected by eviction (e.g. age, gender, marital status, etc) and nature of relationships between the Bacha and surrounding farming communities. The number of households who experienced eviction from the forest was 250, out of which 70 heads of evicted households were selected randomly using a list provided by the local kebele administration.

The collected data were analyzed using both qualitative and quantitative data analysis techniques. Qualitative data were analyzed thematically using themes 
obtained from topical questions and also themes that emerged during qualitative interviews. In order not to lose ideas and keep their coherence and flow, in-depth interviews were tape-recorded and field notes were taken on a daily basis. The collected field notes were organized and analyzed mostly immediately after each fieldwork day and tape recorded notes were also transcribed and analyzed in a similar manner. Quantitative data obtained through questionnaire were coded, categorized and analyzed using Statistical Package for Social Sciences (SPSS) version 20. Statistical results like frequency distributions, means, percentages and standard deviation were used in the analysis.

\section{Findings and Discussion}

\section{Environmental Resources as Mainstay of Livelihood}

One among the defining aspects of the Bacha community is their heavy dependence on environmental resources for their livelihoods including water bodies (like rivers, hot springs, lakes) and trees which provided a variety of economic, medicinal and symbolic functions as emphasized by the focus group discussion participants. Rivers such as Zigna and Gurguta, the major tributaries of the Omo River, provided the Bacha community access to fishing and hippopotamus hunting. The forest also hosts wild animals (e.g. pig and rhinos) which are not hunted by neighboring non-Bacha communities because their religion or traditional belief systems forbid them eating such wild animals. The forest also provided an important source of honey since the unique natural arrangement is suitable for keeping beehives and harvesting a rare quality of honey locally known as bothaesa ${ }^{1}$. Regarding the vital role of the natural environment in fulfilling the livelihood needs of the community, a 57 year-old key informant in Delba kebele said the following:

Wola are the facilities that nature crafted for us when the nonBacha farming community relegated or overlooked us from accesses to manufactured beehives and facilities in the fertile and flat lands. The natural shape of these trees, multiplicity of flowering plants and grass spices, along with the swampy landscapes within the forest created conducive natural space for beekeeping and potential for surplus in honey harvesting.

\footnotetext{
${ }^{1} \mathrm{~A}$ white color honey variety obtained from beehives kept in the forest. Beehives are identified by household name and hence treated as private property, enjoying same protection as any other property.
} 
Environmental resources also contain bio-diversities which are available only in the forest zone and are critical in the production of medicinal products. At the same time, the Bacha did experience social marginalization from their neighboring communities because of their way of life. This was manifested in the ascription that the Bacha should be denied of accesses for ownership of cultivable plot (e.g. labeling them as naturally unfit to integrate to mainstream way of life and shaming their preferences to a deviant consumption habit often sanctioned by followers of more formalized religious organizations). This has implicitly impacted them to remain knowledgeable about alternative medicines and treat sick individuals from both in-group and out-group members. As indicated by informants, lived experiences of confronting exclusion of ownership of asset foundations like agricultural plots and detachment from socially significant fields of social interaction have forced the Bacha people to experiment with herbs and diverse genetic resources in the area and deal with ill-health. Especially their wisdom of treating an illness that frequently harmed their physical wellbeing or total dysfunctions of their body parts (i.e. gerged ${ }^{2}$ ) was symbolic one. The Bacha have developed self-reliance in treating diseases as they do not expect to obtain such services from modern health institutions. Interventions to reorient their healing options, lack of customs in competing state-organized services with surrounding dominant counterparts, and physical inaccessibility among others have kept them away from accessing health institutions.

The forest used to provide stable source of food for the Bacha and is rarely punctuated by drought or flood. The presence of environmental resources and ability to maintain claim over utilization made the Bacha earn stable income and staple food in good quality and quantity as the key informants noted. Marginalization against the Bacaha was manifested by the out-group community in the form of control of assets that are needed to adapt into mainstream life and by the state development agents in the form of disregard to devise model of change that is compatible with their accustomed way of life. This forced the Bacha to retreat into the dense forest - a measure that did not actually lead to impoverishment in economic terms and loss of entitlement on their produce until the conversion of their customary resource zone into conservation land. A 54 yearold male informant said, "the inability to earn a living in flat lands and difficulty to adapt to the mainstream group culture was compensated and made possible by the dense forest which the group adopted very well until recent past." The food that

${ }^{2}$ Disability of body parts often believed to be caused by inability to stay in safe home especially during the rainy season. 
the Bacha people used to consume did remain more or less stable and surplus without being affected in significant ways by seasonal rainfall fluctuations. Therefore, social marginalization did not result in economic marginalization, and as a 36 year-old male informant argues, "physical relegation into hostile escarpment scaled up our endurance to overcome not only challenges from people pushing us but also from pressures of ' nature that affect our very existence." Another 46 year-old female informant also stated "our crops' are less likely to be destructed by natural catastrophes like flood or unforeseen destructions by pests unlike the farming community in the adjacent land-based communities which made non-forest products the center of their livelihoods."

\section{Relationship-Mediating Role of Environmental Resources}

Before the establishment of the national park, environmental resources had played a mediating role in bridging the social gap between the Bacha and non-Bacha communities. Data, obtained through focus group discussions and key informant interviews show that certain inter-community relationships were mediated through the help of valuables obtained from the forestland. For example, the forest used to serve as source of pasture for neighboring farming communities during seasons of extreme drought when they could not find pasture in their immediate surrounding or communal places reserved for grazing; they always considered it indispensable component of their livelihood. The Bacha who had been well adapted to the dense land often avail pasture that was collected from deep in the thick woodland to rescue oxen in particular, which are considered as engine to catalyze survival endeavor of their clients dwelling in the farming community.

The forest also supported a variety of plant medicine used for the treatment of animals. The Bacha elders have knowledge and skills needed to identify and prepare natural veterinary medicines for cattle. According to a 45 year-old traditional healer, the surrounding farming communities depended on the wisdom of the Bacha for the provision of cure for animal diseases in general and provision of the right cure for a snake bite as per the peculiarity of the snake. Snakes in particular caused infection when the farming communities take their cattle to graze along forestlands and attempt to till grasslands reserved for slash and burn agriculture.

Promoting the productivity of cattle was not limited only to availing emergency natural medicine to cure cattle disease, but also in the provision of items for accelerating cattle fattening. A farmer who decides to put aside a cow or 
oxen for fattening, locally known as $d h i k u a^{3}$ would require the wisdom of the Bacha tribe who used to hold monopoly over knowledge of specific plant or tree species used for cattle fattening. Specialists in cattle fattening were knowledgeable in selecting plants that could accelerate the rate of fattening and the wisdom was believed to originate from Bacha's specialists with long-established relationship with the forest.

The Bacha also used to support resources which were highly sought mainly by young members of the farming community. Young members of the farming community who could not inherit adequate size of plots from their parents and need to lead life with shrinking size of land reported to have increasingly resorted into petty trade in order to adapt into the dynamics in their livelihood context. Such items like honey, spices and coffee would be collected by the Bacha people and taken to the nearby markets located in the farming communities and the young farmers would in turn take these items to distant markets in major towns for far higher profits.

In this way, the Bacha used to be a source of livelihood diversification for the non-Bacha community by supplying forest-based products highly demanded by surrounding communities and beyond. Only the Bacha could extract income generating activities from the forest directly as the surrounding farming communities (e.g. Mala) were not adapted to the business of hunting wild honey or keeping beehives in the forest. This task was reserved for the Bacha who have forged a symbiotic relationship with the forest and the wild animals it supported.

In addition, the Bacha used to deliver equipment needed to pursue survival in the traditional socio-economic complexity. These include fashioning grinding stones (a special type of stone - called wotha- used for grinding cereals), as well as wood types naturally molded to fix iron plough and produce tools for cutting trees and clearing farming lands (kalta and walyia). These are desperately needed for the accomplishment of diverse demands of nearby farming communities. These natural resource-based interactions had helped to minimize marginalization of the Bacha by non-Bacha farming people because the survival necessity of the latter depended on products supplied by the former. The products are uneasy to secure in formal markets with cash in, for they are accessible only in traditional arrangements. However, the establishment of the National Park has put an end or halted the medium of human interaction especially for those households who had

\footnotetext{
${ }^{3} \mathrm{~A}$ practice of isolating livestock from herd for the purpose of fattening and then selling to the market
} 
drawn these valuables from the forestland that was later elevated to national park. According to a 43 year-old male informant, "banning access to such physical facilities desperately needed for diversification strategies ... made the restriction unbearable since the livelihoods of both the Bacha and non-Bacha were heavily dependent on it."

\section{Applying the Analytical Model}

Here, we investigate the impact of national park-initiated displacement on the Bacha community using Cernea's Impoverishment Risks and Reconstruction (IRR) model. The six elements of the model (namely, landlessness, joblessness, homelessness, morbidity \& mortality and food insecurity) for which we have data are analyzed to see the multidimensional effects of the displacement on the community.

\section{Land Ownership: Post-and Pre-eviction}

The model assumes that displacement of rural communities for the purpose of establishing national parks leads to reduction in the size of land available to evicted households. In the survey questionnaire, 84\% (59) of the respondents indicated that they had access to private landholdings before displacement. However, the majority (67\%) owned less than 0.5 hectare of land and such small plots were used to cultivate small quantities of sorghum and teff to supplement the then forest-based livelihood. Post-eviction period has shown a substantial increase in the size of land owned by the Bacha people as they gradually moved away from a livelihood based on forest resources and began to practice some sort of settled agriculture. Consequently, $77 \%$ of the respondents indicated that they own more than 2 ha while $17 \%$ own between 1 and 2 ha each.

The community had been identifying itself with forest based products. In this respect, having a huge size of cultivable land for cereal production and having a certificate confirming their legal status was not their interest. But with corresponding restriction or prescription of withdrawal from the conservation zone, desire to own private plot registered in their name started to go high. It then implicitly contributed for increment in the size of private possession of land suited for cropping. This community, that had assembled their life on vast forest, never worried for possession of landholdings registered and certified in private names. However, they began showing interest to obtain legal recognition for their acquired land from the government. Thus ban from operating in the conservation zone declined their possession of trees but increased their size of landholdings that are dedicated for cropping and building assets in private plots. Regarding the situation 
participants in the FGD mentioned an increase in the move by local authorities to expropriate holdings that are suited for cropping. They began to show unprecedented figures even in kebeles that are far from conservation zone. Lessons drawn from the Bacha community who were evicted from the conservation zone inspired similar communities away from the conservation zone to be prepared for unforeseen shock in the wake of national park resettlement and land allocation for investment that has been reordering the customary pattern of resource control and norms of utilization.

This shows that post-eviction has not adversely affected the landownership status of displaced people as they were resettled in an area where there was sufficient agricultural land and this finding is contrary to most displacement programs that often would lead to loss of land by displaced people. However, there are other aspects in which the situation of assets associated with land is examined: status of ownership of trees and associated assets like beehives and coffee in the post-eviction period. Dense trees that supported beehives (and hence honey), and coffee were no longer available in the newly settled land. In the questionnaire, attempt was made to capture the number of trees that each household owned before and after displacement.

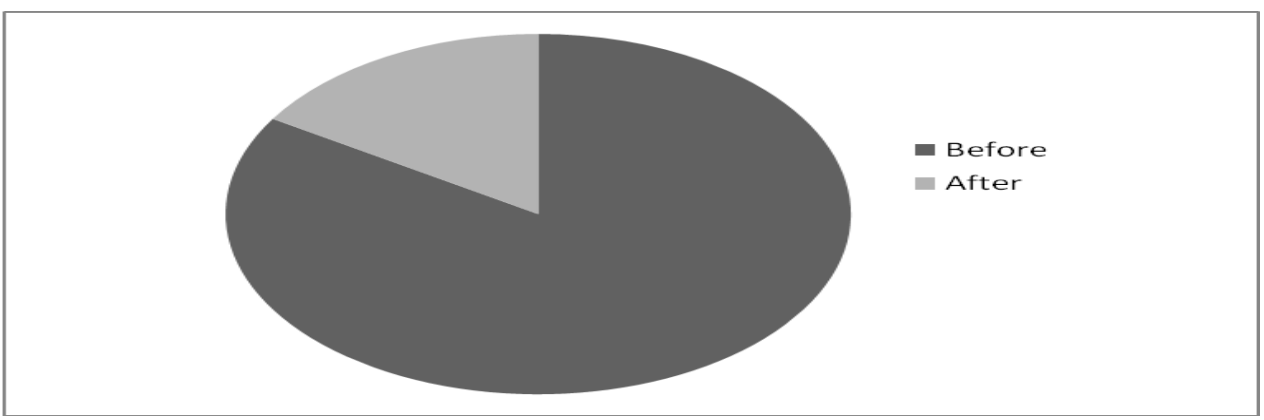

Figure 2: Mean number of trees owned by households: before and after displacement

The average possession of trees owned by households in their pre-eviction situation was 26 with a standard deviation of 9.12820. And the situation in ownership of trees in post displacement period declined with an average tree possession of 4.96 with a standard deviation of 1.56. There was also difference in the number of trees possessed among households surveyed with a range of 16 in pre-displacement context and this figure shrank to 7 in post-displacement period. 
This was due to the fact that the Bacha have been banned from making claims and benefit from trees that later fall under the area ill-marked for national park. Ones they are moved out of the conservation zone, they had limited access to regain their status in areas that already remain under communal ownership. Besides, possession of trees declined in part due to the fact that the Bacha have been resettled in areas where there was less forest cover. Also the demand for wood for house construction and domestic fuel must have reduced the already low tree cover in the areas where they settled. This is also supported by the world wide experience which shows that displacement has the effect of degrading resettled lands and also drastically reducing tree cover (FAO, 2018).

In addition, the underlying socio-cultural and environmental factors contributing to differential possession of trees in the days before installment of norms of restriction according to key informants were inheritance, family arrangement patterns, and demographic realities.

Some households enjoyed relatively greater number of trees resulting mainly from family inheritance or transfer from an ailing close relative who could not manage the trees. Aging was also reported to be one of the factors contributing to the difference in possession of trees that are especially suitable for beekeeping. Family size was also found to be responsible for an increase or decrease in the number of trees owned by households with bigger families being able to supervise and manage more trees than those with smaller families where labor would be a constraining factor. The trees reported to be owned in post-eviction were those found to be naturally grown on plots given by the government. State intervention was lacking to curb long hour travel in search of forestland. Regarding the importance of trees among the Bacha community, a 54 year-old informant who is resident of Delba kebele said the following:

Trees owned by each household were not worshiped for their spiritual or totemic meaning that they used to possess; rather they were basic assets upon which the community secures its livelihood in keeping beehives. For us, land is tree. Our grain is a beehive. But a sudden elevation of trees to national park left us without asset, leaving us uncompensated.

A decrease in the number of trees owned by households has had direct effect on the number of beehives owned and consequently amount of honey produced by the Bacha. As shown in Table 1, the average number of beehives kept before displacement was 266.8 with standard deviation of 91.28203 , and in the 
Deresse Daniel and Abeje Berhanu

post-displacement it dropped to an average of 15.08 beehives per household with a standard deviation of 4.9. This shows a substantial loss of beehives in the postdisplacement period with direct negative impact as expected on the amount of honey produced (a reduction of as much as 4.5 times of pre-eviction level) and this has had serious implications on the livelihood situation of the Bacha people following eviction from their ancestral forestland.

Table 1: Mean number of beehives owned and amount of honey produced by displaced households in 2005/06 and 2011/12

\begin{tabular}{|c|c|c|c|}
\hline \multicolumn{4}{|c|}{ Number of beehives owned } \\
\hline \multicolumn{2}{|c|}{ Before displacement } & \multicolumn{2}{|c|}{ After displacement } \\
\hline Mean & Standard deviation & Mean & Standard deviation \\
\hline 266.8 & 91.3 & 15.08 & 4.9 \\
\hline \multicolumn{4}{|c|}{ Amount of honey produced (kg) } \\
\hline \multicolumn{2}{|c|}{ Before displacement } & \multicolumn{2}{|c|}{ After displacement } \\
\hline Mean & Standard deviation & Mean & Standard deviation \\
\hline 273.9 & 82.8 & 59.7 & 19.5 \\
\hline
\end{tabular}

Eviction from the forestland not only dispossessed the Bacha of ownership of beehives, trees and the produces they always obtained from the forest but also coffee and spices which were also sub-divided among households. They used to be privately owned just like trees. 'Wild coffee', as outsiders label it, was not without private control. The Bacha gave coffee trees the care they deserve to obtain a meaningful harvest every year. 40 year-old woman explained that coffee used to play a vital role in the life of the Bacha not just in economic terms but also in making the people feel proud of their engagement in collecting wild coffee. The growing demand by the market for forest coffee, according to the informant, had had the potential to reduce the social exclusion that is being ascribed to the Bacha by non-Bacha communities and uplift their prestige. Interaction with neighboring farmers via exchange of coffee and spices brought the Bacha closer to farming communities that used to treat them as less equals. But all this now seemed to have gone as the Bacha's control of wild coffee ended following their eviction from their ancestral land.

\section{State of Morbidity and Mortality due to Loss of Ethno-Medicine Resources}

The literature on displacement is replete with a description of the psycho-social impacts of displacement on displaced people, especially their growing exposure to 
ill-health resulting from spread of water-borne diseases such as malaria and schistsomiasis (Ayalew and Getachew, 2009). Kassahun (2009) studied the social effects of hydro-electric power induced displacement, resulting from the construction of the Gilgel Gibe hydro electric dam, and the spread of malaria was found to be a major health problem for the displaced people. Unsafe water supply and deteriorating quality in access to potable water enhances the risk to epidemics (Cernea, 1999). The FGD participants indicated that Bacha's health risks due to restriction to forestland increased in the post-eviction period. This in part is due to the fact that the Bacha have always been dependent for the treatment of physical pathologies on forest-based products. According to a 51 year-old traditional healer, knowledge of indigenous medicine enabled them to develop effective treatment for different kinds of diseases not just for members of the Bacha community but also for the non-Bacha members. However, eviction has adversely affected their health security and alienated them from forest-based health insurances.

The national park has created limited employment opportunities for some Bacha youth and this in turn helped the National Park to intensify control over the forestland. The employment of some Bacha youth in the park as guards has brought an end to the possibility of the community accessing benefits from the forestland. All kinds of activities including collection of herbs, harvesting honey and collection of wood for domestic fuel are now banned. Regrouping them along with indigenous farming communities and placing them on edges of resettlement sites hosting settlers originating from Wolayta and Hadya zones following the intra-regional resettlement launched in 2004 further enhanced their vulnerability to diverse risks like the spread of water-borne diseases. As they began to compete with farming communities for resources, insufficient access of potable water for both human and animal use triggered large scale suffering. This situation was described by the 42 year-old administrator Seri Kebele as follows:

The Bacha used to live in scattered, migratory-like life style far from the congested settlement of farming communities and their members were most of the time spending the whole day moving within the forest, easily accessing natural springs for drinking and also for keeping personal hygiene. Pure and uncontaminated water bodies were ample in the forestland enabling water accessibility. But displacement has made them vulnerable to water shortages by putting pressure on the community which has already been suffering from shortages. It led to worsening quality of water points. 
As noted by Cernea (1999), health risks are not only physiological but also social and psychological. In this regard, it is worth noting how psychosocial wellbeing would come under the risk of insecurity. In this case, the underlying cause for the prevailing sense of insecurity among the Bacha is rooted in the loss of the tradition of resolving conflict in an anonymous manner under the deep cover of forests according to a 35 year-old key informant working in the Woreda Office of Justice. But now conflicts are handled in an open space where everyone - Bacha and non-Bacha - are exposed to public scrutiny, especially by agents of the state such as kebele officials. Lack of access to the forestland has taken away the Bacha's sense of protection, since before displacement a person who had committed crime (e.g. theft) could easily disappear in the dense forest. Leading life in the jungle was sometimes a strategy used by some Bacha who had committed wrong doing. This privilege is no longer available to the Bacha community who find themselves surrounded by farming communities and local state officials who historically consider the Bacha as unfit to adapt to be modern.

\section{Risks of Homelessness}

The Bacha community, who are displaced by the Chebera-Churchura National Park, are reported to have faced risks related to the condition of homelessness. FGD participants said that although they were not accustomed to constructing and living in a house similar in structure to that of farming communities, they used to use forests as source of shelter. But now, they are in the open space with no forest trees to serve as shelters or no skill to construct houses. Therefore, the feeling of homelessness is creeping on them. A 54 year-old key informant describes the Bacha's conventional view of home and the difficulty of adjusting to the new home structure:

Our home was our forest. There was no special privilege offered to a person as per the corresponding quality of home and fences instilled. Thus, the community didn't develop skills on how to build a house in a manner that the farming community has always been adapted to. The source of social pride and strength lied in the wisdom one displayed while assembling beehives and maintaining efficiency in harvesting the most valued product, honey by men and caring for wild coffee for women.

Attempts to develop new skills from the farming community have been unsuccessful as stated by FGD participants. This has been due to two major 58 
reasons. The first one was Bacha's lack of participation in the informal association called iddir where farmers exchange views and get help from friends when they plan to build a house. The Bacha, who have been administratively lumped together to the farming community but socially unadjusted, could not easily win membership and claim the benefits vital for the smooth functioning of their households. In addition, post-displacement has necessitated rearranging the household and also house structure to fit to new realities. For example, polygamy as an established practice among the Bacha community would now require every male adult to build a house for each wife. However, lack of sufficient plot coupled with constraints in responding to the desires of every woman under one's headship in the new context further deepen the magnitude of risks. Therefore, the feeling of homelessness has become a deeply troubling phenomenon for the Bacha.

The above situation has made younger wives to seek refuge in the home of older men or decide to flee into family homes after dissolving marriage. Those women joining older men as a second wife would receive junior treatment by the "senior" wife and at times would be treated like a slave, devoid of any say on matters concerning household management.

The above situation has made some of the younger members of the household especially women homeless and often forced them to share houses with the elderly. Thus the situation of homelessness is somehow changing household and marriage arrangements and the ways by which inter-household relations were structured.

\section{Social Disorganization}

It is reported in the literature on displacement that conservation-induced displacement contributes to fragmentation of communities and disrupts interpersonal ties (Cernea, 1999). This is not an exception to the Bacha. For example, the institution of dago is one among those threatened by displacement and eventually vanished as the national park tightens restrictions on the forestland. Dago is an indigenous association by which households seek to mobilize extra labor in times of need (e.g. building huts, collection of honey). It has had dual function, according to key informants: (1) strengthening inter-household relations and promoting in-group solidarity, and (2) serving as a training-platform for authority-aspiring individuals to get hands-on leadership skills in the community. Dislocation from forestland and transition-induced disappearance of their survival strategy has been found to impaire this institution. Dispersal across farming villages in the midst of 'out-group' counter parts was a challenge to reinstitute social organization which had played a symbolic role while meeting their socio- 
Deresse Daniel and Abeje Berhanu

economic needs. Besides, this social organization was better suited for this group when they dealt with matters in the forest than in their periods of post-eviction.

Attempts to get engaged in similar social organizations operating in the farming community seemed to have been ineffective due to insufficient skill of integration. The absence of the unique contribution the Bacha community provided from the forest contributed to the loss of interest among the farming community when it comes to accepting the Bacha into their social organization.

Another area where social disruption took place is declining sense of neighborliness among the Bacha as a result of settling in the new environment. This was captured by the household questionnaire in which the majority of the respondents indicated that the feeling of neighborliness has suffered following displacement. As can be seen in Table 2, the sense of neighborliness suffered a serious blow(from $51.4 \%$ to $12.8 \%$ ) as the Bacha were now overcome by feelings of insecurity and disorientation resulting from their forced integration into the farming communities when they were resettled. Instead, participation in formal organizations like the kebele administration has become the norm for which the Bacha are not prepared because of their long-standing tradition of living in the forestland with minimal contacts with agents of the state.

Table 2: Respondents' perception of neighborliness: Pre-and post-displacement

\begin{tabular}{|l|ll|ll|}
\hline \multirow{2}{*}{$\begin{array}{c}\text { Sense of } \\
\text { neighborliness }\end{array}$} & \multicolumn{2}{c|}{ Before displacement } & \multicolumn{2}{c|}{ After displacement } \\
\cline { 2 - 5 } & Frequency & Percentage & Frequency & Percentage \\
\hline High & 36 & 51.4 & 9 & 12.8 \\
\hline Moderate & 23 & 32.9 & 24 & 34.9 \\
\hline Low & 11 & 15.7 & 27 & 38.6 \\
\hline Total & 70 & 100 & 70 & 100 \\
\hline
\end{tabular}

\section{State of Joblessness Due To Dislocations from Customary Claims and Contacts}

Loss of forest-based assets has created the risk of losing income and is also likely to make some of the forest-based skills dysfunctional. A 35 year-old male informant, engaged in petty trade (such as selling coffee and spices) at the time of the data collection said that lack of jobs is a serious issue especially for young Bacha men and women. Joblessness in the context of youth was found to be severe mainly due to loss of social networks and disconnection with their customary 
mode of survival. Similarly, a 45 year-old female informant indicated that the forest had given them unrestricted access to income-generating activities like picking coffee and spices. Those who had medicinal skills for detecting possible health risks (e.g. snake biting), like the 45 year-old male informant, are no longer making use of their skills to earn income as they could not practice their traditional trade in the forest because of the ban put by the national park.

The above qualitative data also finds support from results of the survey questionnaire that asked respondents whether their access to non-farm jobs and income generating activities has increased following displacement (Table 3).

The majority $(65 \%)$ of the respondents indicated that non-farm jobs associated with natural resources (e.g. honey collection, harvesting coffee beans, etc) were available before displacement. However, in the post-eviction period, respondents' perception of job availability declined from $65 \%$ to $17 \%$ with the majority of them (64\%) saying that jobs are currently not available. The national park has put in place stringent rules that restrict access to forest resources and this in turn has constrained the Bacha's access to non-farm jobs, according to a 46 year-old male informant. Besides, both the Bacha and non-Bacha communities are increasingly accessing modern veterinary services for their livestock and this has reduced the demand for indigenous medicinal plants which the Bacha had been producing for generations before their eviction.

Table 3: Availability of non-farm jobs: Pre-and post-displacement

\begin{tabular}{|l|l|l|l|l|}
\hline \multicolumn{1}{|c|}{ Non-farm jobs } & \multicolumn{2}{c|}{ Before displacement } & \multicolumn{2}{c|}{ After displacement } \\
\hline & Frequency & Percentage & Frequency & Percentage \\
\hline Available & 46 & 65.7 & 9 & $\mathbf{1 2 . 9}$ \\
\hline Somewhat available & 16 & 22.9 & 20 & $\mathbf{2 8 . 6}$ \\
\hline Not available & 8 & 11.4 & 41 & $\mathbf{5 8 . 6}$ \\
\hline \hline Total & $\mathbf{7 0}$ & $\mathbf{1 0 0}$ & $\mathbf{7 0}$ & $\mathbf{1 0 0}$ \\
\hline
\end{tabular}

\section{Status of Household Food Insecurity}

Food insecurity refers to a lack of access to enough good, healthy, and culturally appropriate food (Forward, 2017). More specifically, food insecurity is common among households displaced by man-made (conservation-induced) or natural 
disasters (drought and famine). Among the different measures of food insecurity, reducing/ skipping meals is one of the measures of food security as introduced by USDA in 2006. Thus, very low food security/food insecurity is defined as a condition where "at times during the year, eating patterns of one or more household members were disrupted and food intake reduced because the household lacked money and other resources for food" (USDA, 2018).

Households evicted from the Chebera-Churchura National Park have reportedly faced increased risk of food insecurity. Pankhurst et al (2013, p. 241), citing Cernea (2000) noted that "during physical relocation, sudden drops in food crop availability and incomes are predictable. Subsequently, as rebuilding regular food production capacity may take years, hunger and under-nourishment tends to become a lingering long-term effect." The state of food insecurity of Bacha households could be considered using two indicators: volume of assets stored by the Bacha community in the post-displacement period and number of meals available for household members. It is noted by participants of FGD that the Bacha had the tradition of storing food (e.g. honey) by digging holes around the homestead or deep in the forest. Especially, women who are in charge of preparing meals used to store root crops, coffee and other valuables. However, this practice has ceased as the quantity and quality of harvested forest-based products declined sharply resulting from lack of access on the part of the Bacha to forestland. There is now a modest shift towards producing and storing cereals but then the volume of cereal production by the Bacha is still low and hence does not meet a household's demand for food year round. As a result, food insecurity has become a new phenomenon for the Bacha - something they hardly experienced before because of all year round availability of forest-based resources before eviction.

Also, there has been a decline in the amount of meal available on a daily basis for household members. The difference in the number of meals between preand post-displacement periods is captured by results of the household survey displayed in Table 4. 
EJOSSAH Vol. 14 No. 2

December 2018

Table 4: Number of meals per day: Pre-and post-displacement

\begin{tabular}{|lcccc|}
\hline $\begin{array}{c}\text { Number of } \\
\text { meals per } \\
\text { day }\end{array}$ & \multicolumn{2}{c}{ Before Displacement } & \multicolumn{2}{c|}{ After Displacement } \\
\cline { 2 - 5 } & Frequency & Percentage & Frequency & Percentage \\
\hline $\mathbf{1}$ & 2 & 3.2 & 24 & 36.9 \\
\hline $\mathbf{2 - 3}$ & 27 & 43.6 & 26 & 40.0 \\
\hline$>\mathbf{3}$ & 33 & 53.2 & 15 & 23.1 \\
\hline Total & 62 & 100.00 & 65 & 100.00 \\
\hline
\end{tabular}

As can be observed from Table 4, more than half of the respondents (53.2\%), out of the 62 who responded to the question, indicated that they used to have their meals more than 3 times a day but this figure declined to $23 \%$ in postdisplacement, while those having one meal only increased from $3.2 \%$ (before displacement) to $37 \%$ (post-displacement). Reduction in the number of meals at the household level is one indicator of the creeping food insecurity among the Bacha and this in turn is a sign of the growing material impoverishment that is likely to face the community as a whole. Not only the frequency of meals per day declined following eviction but also did the composition of meals. For example, honey, which used to be part of the meals, is mostly absent from the Bacha's daily meals. Inability to collect food from the forest, failure to adapt to the farming way of life (e.g. refusal to apply chemical fertilizer on their crop fields resulting from the belief that they would die if they grow crops using chemical fertilizers) and inherent vulnerability of the newly adapted way of life - crop farming - to the vagaries of nature were mentioned by male FGD participants as main reasons for the growing food insecurity among the displaced Bacha.

\section{Bacha's Coping Strategies}

Following displacement, the Bacha people have adopted a series of coping strategies to deal with the undesirable effects of forced displacement. These coping strategies include: migration, seeking wage labor, illegal logging, and conversion into new religion. Each is discussed briefly below.

One of the defining features of migration by the Bacha is that it does not involve long-distance move (e.g. move to towns or gold mining sites in Dima which is found in Gambella region). But their migration is characterized by a move to neighboring farming communities who have already hosted other Bacha that left 
the forest on their own before they were forcefully pushed by the national park. A good number of the Bacha people had already moved to kebeles like Albe-Agare, Oshka-Dencha, and Ginba-Agaree, according to participants of FGD. The presence of the Bacha kinsmen in these kebeles has helped other Bacha people to consider migration proactively and seek refuge in the face of forceful eviction. It should be noted that migration on the part of individual Bacha is not new (since they used to move out of the Bacha country in times of intra-group conflicts or feuds) but this time the possibility of return is not there since they left the forestland for good.

To overcome the destabilizing effect of the national park on their livelihood, the Bacha especially young people are now taking up constructionrelated jobs as alternative means of making a living. In this regard, the national park has created opportunities for the local people to engage in road construction, especially roads crisscrossing and passing through the national park to facilitate travel by tourists within the national park. Park authorities also encourage the Bacha to engage in activities undertaken by the park as part of government efforts to integrate the Bacha into a way of life that is not dependent on the forestland. The reluctance of the farming community to participate in the park (because they associate the park with the socially marginalized Bacha) has also created opportunities for the Bacha to take active part in the road works with little or no competition from the farming communities. A World Bank-funded road project undertaken in Konta Special Woreda has also benefited the Bacha who were found to be more willing than the farming community to work on the physicallydemanding road projects.

Another coping strategy adopted by the Bacha is illegal cutting and harvesting of trees belonging to the national park. The Bacha have started to make use of their deeper knowledge of the forest by identifying and cutting trees that would be used in the production of local timber and other wood products. Sometimes, they collaborate with farming communities to harvest timber and collect firewood and charcoal illegally from the forest. The Bacha are now directing their anger at the national park (e.g. due to ill-treatment of park officials during eviction) by engaging in indiscriminate cutting of trees and by helping others steal wood from the protected forest. Similarly, Dessalegn (2001) described rural communities' reaction following the fall of the military regime in 1991 that took a form of violence against the environment or 'ecoviolence' where illegal harvesting of forests and deliberate burning of national parks became a common practice. However, it should be noted that Bacha's resistance against the establishment of Chebera-Churchura National Park did not escalate to such a level. 
Some Bacha households who are struggling to make transition to farming are still dependent on the forest for their livelihood, though, they would be arrested and fined if they are found cutting trees or collecting wood from the forest which they had been protecting and caring for it for generations. Because of this and many other grievances such as the failure of local officials to deliver on their promise to support the evicted Bacha, their sense of belonging to and respect for trees is gradually being eroded with adverse impacts on the park's conservation activities.

Integration with institutions like the Protestant religion to which they were outsiders has recently become a phenomenon which the group under eviction has increasingly begun to consider. Dispossession due to alienation from the lands of ancestors that could provide them with spiritual and physical needs has forced them to look for certain social arrangements that are established and operated by the surrounding non-Bacha community. The Bacha have resisted, for generations, the intrusion of new religions such as Protestantism into the area but displacement has exposed them to influences of followers of Protestant religion. A 46 year-old Bacha, who is converted recently into Protestantism, explains the reasons as follows:

My adoption of protestant religion was not motivated due to the spiritual or doctrinal superiority of the religion to which we are currently following. It is rather to benefit from opportunities being created after membership, for most of the social and economic benefits vital for rebuilding our livelihoods destroyed by displacement are tied to membership to religious organizations or indigenous associations such as Iddir.

Therefore, post-displacement coping and adaption mechanisms not only include engagement in livelihood activities designed to ensure survival but also increased aspiration for integration into institutions which can break the barriers of history of social exclusion. Utilizing physical facilities (e.g. schools, health services) has become a central element for permanent integration and adaptation to ensure a more stable livelihood. The new adaptation strategy is one of determination to benefit from facilities (e.g. health, education, employment, etc) to which the Bacha had very little experience before. 


\section{Concluding Remarks}

The establishment of the Chebera Churchura National Park in 2005 has resulted in the displacement of the Bacha from their ancestral land and subsequent loss of their forest-dependent livelihood. Accessing forest resources (e.g. forest honey and medicinal plants) has now become illegal. Farming has gradually become an inevitable way of life, though lack of farming skills on the part of the Bacha has slowed their adaptation to the new livelihood system. In addition, the surrounding farming communities' historically-held negative attitude toward the Bacha is negatively affecting their transition to farming activities. Bacha's postdisplacement conditions were assessed using Michael Cernea's IRR model that showed that the Bacha people have faced deteriorating socio-economic prospects: low social status in the host community and expropriation of the right to exploit forest-based natural resources, though their access to land has increased. However, because of limited farming skills the Bacha could not put the available land to productive use so that their livelihood would be improved.

The empirical evidence suggests that resettlement often leads to further marginalization of minority groups (Dessalegn, 2003; Pankhurst et al., 2013) and this indeed has been the case with the Bacha minority group. For them, the social costs of displacement (e.g. vulnerability to further marginalization by farming communities and weakening of bonds of neighborliness), which are not specifically addressed by the IIR model, have been weighing heavily on their efforts to adapt to the new environment, albeit it has been already settled by agriculturalists.

All in all, there is an urgent need for local government intervention by way of, for example, farm skill training and provision of farm tools and other necessary inputs so that the Bacha can gradually do away the shackles of social stigmatization and economic marginalization. 


\section{References}

Ayalew Gebre and Getachew Kassa. (2009). The effects of development projects on the Karrayu and the Afar in the mid-Awash Valley. In Alula Pankhurst and Francois, P. (Eds.), Moving people in Ethiopia: Development, displacement and the state (pp. 66-80). Cape Town : James Currey.

Brokington, D. (1998). Landloss and livelihoods. The Effects of eviction on pastoralist moved from the Mkomazi game reserve, Tanzania. London: London University College.

Cemea, M. (1999). "The need for economic analysis of resettlement: A sociologist's view." In Michael M. Cernea (Ed.), The economics of involuntary resettlement. Washington D.C: World Bank Publication.

Cernea, M. (2005a). "Concept and method: Applying the IRR model in Africa to resettlement and poverty" In I. Ohm and Gebre Y. (Eds.), Displacement risks in Africa. Refugees, resettlers and their host population. Kyoto: Kyoto University Press.

Dereje Woldeyohannes. (2006). Diversity, distribution, and relative abundance of the avian fauna of Chebera- Churchura (Unpublished M.A thesis). Addis Ababa University, Addis Ababa.

Derese Daniel. (2013). The impact of national park on the livelihoods of indigenous minorities: The case of Bacha community in Chebera Churchura national park, SNNPR. (Unpublished MA thesis). Department of Sociology, Addis Ababa University.

Desalegn Rahmato. (2001). Environmental change and state policy in Ethiopia: Lessons from past experience (FSS monograph series, no 2). Addis Ababa: Forum for Social Studies.

Ethiopian Wildlife Conservation Authority (EWCA). (2015). State of conservation report of the World Natural Heritage Site, Simien Mountains National Park (Ethiopia). Addis Ababa: Author.

Food and Agricultural Organization of the United Nations. (2018). Managing forests in displacement settings.

Retrieved from http://www.fao.org/3/I8309EN/i8309en.pdf

Food Forward. (2017). What is food insecurity? Food security? Retrieved from https://foodforward.org/2017/10/what-is-food-insecurity/

Hakim, R. (2000). "From corn to cotton: Changing indicators of food security amongst resealed Vasavas." In M. Cernea and C. McDowell (Eds.), Risks and Reconstruction. Washington, DC: The World Bank. 
Deresse Daniel and Abeje Berhanu

Horowitz, M., \& M. Salem-Murdock (1993). Development-induced food insecurity in the middle Senegal valley. Geo Journal, 30(2), 179-184. Retrieved from https://reliefweb.int/report/world/

Julian, H., Alain. G., Theodore. M., Lloyd. S., \& Barton. W. E. (1963). Conservation of nature and natural resources in Ethiopia (NS/NR/47, WS/1263.146/NS). UNESCO.

Kassahun Kebede. (2009). "Social dimensions of development-induced resettlement: The case of the Gilgel Gibe Hydro-electric Dam". In Alula Pankhurst and Francois P. (Eds.), Moving People in Ethiopia: Development, displacement and the state. Cape Town: James Currey.

Maija, H. (2007). Assessment of the local economic impacts of national park tourism: the case of pallasd-ouanstunturi National park. Available at http://www.ifpri.org/yubs/ib/ib3.

Mathur, H. M. (1998). "Impoverishment risk model and its use as a planning tool.'In H. M. Mathur and D. Marsden (Eds.), Development projects and impoverishment risks: Resettlement project-affected people in India. Delhi: Oxford University Press.

Meseret, A. (2006). History and status of Africa elephant and human-elephant conflict in chebera-churchura national park, Ethiopia (Unpublished M.A Thesis). Addis Ababa University, Addis Ababa.

Nayak, R. (2000). Risks Associated with landlessness: An exploration towards socially friendly displacement and resettlement. In M. Cemea (Ed.), The economics of involuntary resettlement. Washington D.C: World Bank Publication.

Pandey, B. (1996). Impoverishment risks: A case study of five villages in coal mining areas of Talcher, Orissa (Paper presented at the workshop on Involuntary Resettlement and Impoverishment Risks). New Delhi.

Pankhurst, A., Mengistu Dessalegn, V. Mueller, \& Maji Hailemariam. (2013). "Migration and resettlement: Reflections on trends and implications for food security". In Dessalegn Rahmato, Alula Pankhurst and Jan-Gerrit van Uffelen (Eds.), Food security, safety nets and social protection in Ethiopia. Addis Ababa: Forum for Social Studies.

Peluso, N. L. (1993). Coercing conservation? The politics of state resource control. Global Environmental Change, 3(2), 199-217.

Piguet, F., \& Pankhurst A. (2009). Migration, resettlement and displacement in Ethiopia: A historical and spatial overview. In Alula Pankhurst, \& 
Francois P. (Eds.), Moving People in Ethiopia: Development, Displacement and the State. Washington D.C: World Bank Publication.

Reddy, I.U.B. (1998). Involuntary resettlement and marginalization of projectaffected-persons: A comparative analysis of Singrauli and Rihand power projects. In H.M. Mathur and D. Marsden, (Eds.) Development projects and impoverishment risks: Resettlement project-affected people in India, Delhi: Oxford U.P.

Sato, J. (2000). People in between: Conversion and conservation of forestlands in Thailand. Development and Change, 31, 55-77.

Schmidt-Soltau, K. (2003). Conservation-related resettlement in Central Africa: Environmental and social Risks. Development and Change, 34, 525-551.

Tadesse Berisso. (2009). Planning in resettlement in Ethiopia: The experience of the Guji Oromo and the Nechsar National Park. In Alula Pankhurst and Francois Piguet (Eds.), Moving people in Ethiopia: Development, displacement and the state. Washington D.C: World Bank Publication.

Turton, D. (1987). The Mursi and National park development. In D. Anderson and R. Groove (Eds.), Conservation in Africa: People, policy and practice. Cambridge: Cambridge University Press.

United States Department of Agriculture (USDA). (2018). Food security in the USA. Retrieved from https://www.ers.usda.gov/topics/food-nutritionassistance/food-security-in-the-us/measurement.aspx

Walter, F. (1991). Power and powerlessness: Development projects and displacement of Tribals. Social Action, 4(3), 243-270. 